\title{
A Chronic Inguinal Intertrigo Revealing Inverse Psoriasis
}

\author{
Mrabat Samia $^{1}{ }^{*}$,Laamari Kaoutar ${ }^{1}$, Douhi Zakia ${ }^{1}$, Elloudi Sara $^{1}$ Baybay Hanane $^{1}$ Mernissi Fatima Zahra $^{1}$ \\ ${ }^{1}$ Department of Dermatology, University Hospital Hassan II, Fès, Morocco \\ * Corresponding Author: Mrabat Samia, Department of Dermatology, University Hospital Hassan II, Fès, Morocco. \\ E-Mail:samiamrabat91@gmail.com
}

Received date: October 02, 2019; Accepted date: October 20, 2019; Published date: October 28, 2019

Citation: Mrabat S., Laamari K., Douhi Z., Elloudi S., Baybay H., Mernissi FZ., A Chronic Inguinal Intertrigo Revealing Inverse Psoriasis

J.Dermatology and Dermatitis . 4(2);DOI: 10.31579/2578-8949/050

Copyright:@ 2019 Mrabat Samia, This is an open-access article distributed under the terms of the Creative Commons Attribution License, which permits unrestricted use, distribution, and reproduction in any medium, provided the original author and source are credited.

\begin{abstract}
Plaque psoriasis is typically localized to extensor surfaces of the skin, whereas inverse psoriasis is defined by its localization to intertriginous areas where two skin surfaces meet. It can be localized to the axillae, groin, genital area, umbilicus, postauricular area, intergluteal, antecubital and popliteal fossae.
\end{abstract}

Key words: Psoriasis; intertrigo; inverse; folds

\section{Introduction}

The lesions are well demarcated with less or no scaling compared to classical plaque-type psoriasis [1,2]. We report a case af inverse psoriasis that had been mistaken for a mycotic intertrigo.

A 38 years old woman presented with a localized inguinal pruritus evolving for three years, the patient had already received local and oral antimycotic treatment with no improvement. The clinical examination found a well limited unilateral inguinal intertrigo, dermoscopy showed scales with regularly distributed, dotted vessels on a light red background. The rest of the skin examination, nails and scalp showed no abnormalities. The patient was then treated with topical corticosteroid with great improvement.

Figure 1

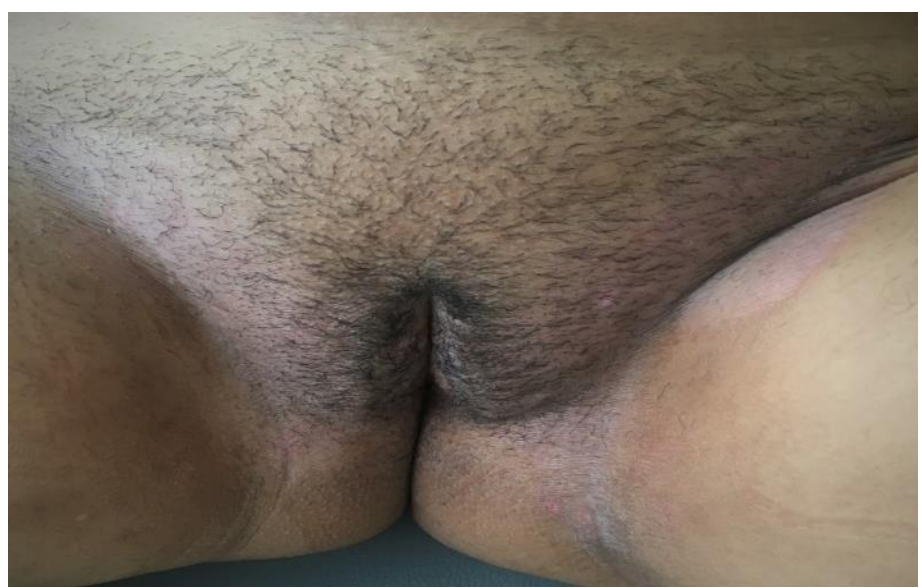

Figure 2

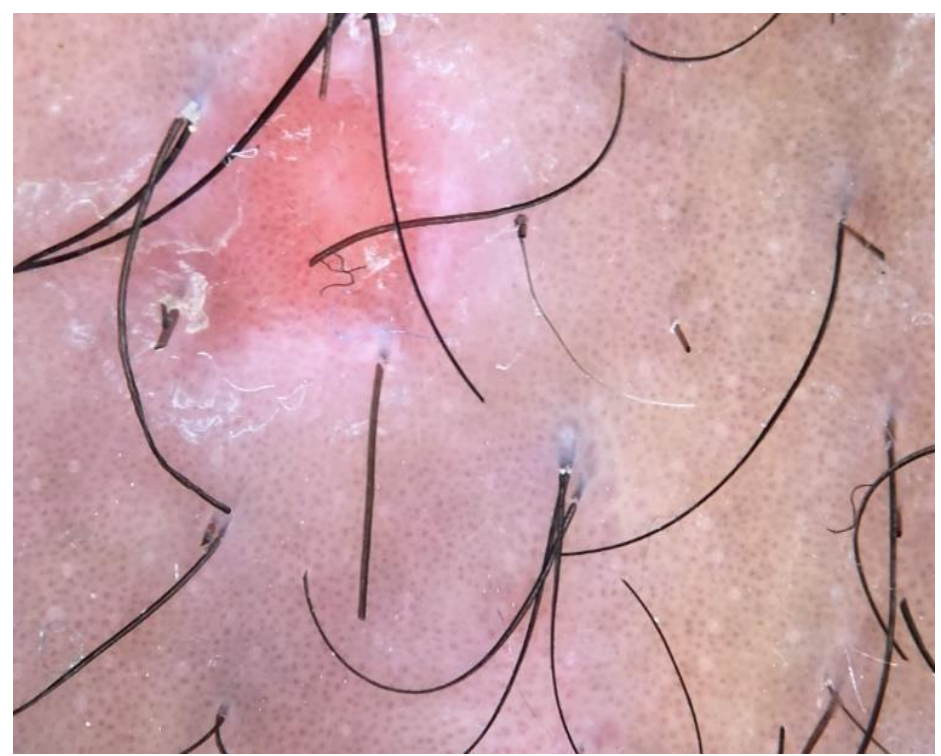

References:

1. S. H. Omland, R. Gniadecki.( (2015) ) Psoriasis inversa : A separate identity or a variant of psoriasis vulgaris? Clinics in Dermatology 33, 456-461.

2. Wang G, Li C, Gao T, Liu Y (2005) Clinical analysis of 48 cases of inverse psoriasis : A hospital based study. Eur J Dermatol. 15 :176178 